\title{
Evaluation of Uterine Involution by Rectal Palpation and Ultrasonography in Peripartum Nutritional Supplemented Jaffarabadi Buffaloes
}

\author{
K. B. Vala* , F. S. Kavani, R. J. Raval and P. H. Tank \\ Department of Veterinary Gynaecology \& Obstetrics, College of Veterinary Science \& Animal \\ Husbandry, Junagadh Agricultural University, Junagadh-362001, India \\ *Corresponding author
}

\begin{tabular}{l} 
K e y w o r d s \\
$\begin{array}{l}\text { Jaffarabadi buffalo, } \\
\text { Transitional nutrition, } \\
\text { Uterine involution, } \\
\text { Ultrasonography, Uterine } \\
\text { horn biometry }\end{array}$ \\
\hline Article Info \\
\hline $\begin{array}{l}\text { Accepted: } \\
\text { 18 May } 2018 \\
\text { Available Online: } \\
\text { 10 June } 2018\end{array}$ \\
\hline
\end{tabular}

\section{Keywords}

affarabadi buffalo,

horn biometry

une 2018

\section{A B S T R A C T}

Studies on influence of peripartum nutritional supplementation on uterine involution and postpartum fertility are meager in Jaffarabadi buffaloes. Hence this investigation was undertaken at Cattle Breeding Farm, JAU, Junagadh on 40 advanced pregnant Jaffarabadi buffaloes of 2-4 parity. The animals were divided into two equal groups, viz., control and treatment groups. The control goup was maintained on standard routine farm feeding, while the animals of treatment group received additional daily oral supplements of $50 \mathrm{~g}$ chelated mineral mixture and $150 \mathrm{~g}$ bypass fat along with concentrate for 6 weeks prepartum till 2 weeks postpartum. The bypass fat was then given@15 g/litre of milk produced limiting maximum up to $200 \mathrm{~g} / \mathrm{head} / \mathrm{day}$ till 60 days postpartum. All the buffaloes were subjected to per rectal gynaeco-clinical and ultrasonographic examinations, using hand calibration technique and a 5.0-7.5 MHz linear array transducer on day 7, 15, 30, 45 and 60 postpartum. On day 7 postpartum, the gravid and non-gravid uterine horns of both the groups were lying cranial and ventral to pelvic brim in abdominal cavity as large, soft, flabby water bag like structures, and were found to be larger than the cervix. In the subsequent days postpartum, the genitalia reduced even further, regaining the tonicity and elasticity. The gross involution of the uterus was observed to be completed by $37.00 \pm 0.56$ and $32.75 \pm 0.57$ days $(\mathrm{p}<0.05)$ in the buffaloes of control and treatment groups, respectively. The USG screening on day 7 postpartum revealed the wall of the cervix as a bright hyperechoic structure, while its lumen was found to be hypoechoic with bright hyperechoic spots denoting the cervical folds. The wall of the uterine horns was hyperechoic with anechoic lumen with hyperechoic spots (lochia). The echogenicity got pronounced with an increase in postpartum intervals till day 45 postpartum. The uterine caruncles were represented as a bright hyperechoic structures. The mean diameters of cervix and past gravid and non-gravid uterine horns were recorded to be reduced gradually and significantly from day 7 to days 15 and 30 postpartum, and thereafter the mean diameters were reduced non-significantly till day 60 postpartum. By 120 days postpartum, 50 and $85 \%$ animals in control and treatment group had conceived suggesting beneficial effect of peripartum nutrients supplementation. 


\section{Introduction}

Buffaloes in India have established themselves superior to crossbred cows in many respects. However, low reproductive efficiency, as evident from delayed first postpartum estrus and conception, prolonged service period resulting in long inter-calving period and seasonality in breeding etc., is a major constraint that leads to reproductive problems like subestrus, anestrus and repeat breeding in these animals and hence there is a dire need to improve the level of fertility in dairy buffaloes. Duration of postpartum anestrus has an important influence on reproductive performance. Factors such as limited energy intake, lower body reserves, and postpartum diseases can delay the uterine involution and thereby return to cyclicity.

Therefore, the event of parturition and the time thereafter play a key role in resuming the reproductive life and come back to cycle. A trouble-free calving predisposes to prompt resumption of postpartum ovarian activity. Ideally, this should be followed by a minimal period of negative energy balance (NEB). The nutritional, managemental and environmental factors have impact on fertility. Transitional period and early postpartum phase in particular exerts biological and physiological stress on the dam (Setia et al., 1992).

During puerperal period there are different activities such as shrinking of the uterus with regular myometrial contractions which promote the elimination of lochia and there is an overall reduction of smooth muscle mass (Salma et al., 1999). The structure of the endometrium and deeper layers of the uterine wall get restored along with resumption of ovarian activity and elimination of bacterial contamination (Noakes, 2001). Smooth muscles play an important role in the expulsion of the uterine contents and reduction of the uterine size (Bacjsy et al., 2005). The greatest change in the uterus occurs within a few days postpartum. Uterine involution and diameter of uterine horns can be monitored directly by palpation per rectum with precalibrated hand (Suthar et al., 2004), or using the transrectal real time ultrasonography (Theodore et al., 2016). However such studies are lacking in world famous Jaffarabadi buffaloes. Hence this investigation was aimed to evaluate the postpartum uterine dynamics with and without peripatum nutrients supplementation and its effect on postpartum fertility in Jaffarabadi buffaloes in its home tract.

\section{Materials and Methods}

The present investigation was carried out from June 2015 to December 2017 at the Cattle Breeding Farm, JAU, Junagadh, Gujarat (India). Total 40 healthy advanced ( 8.5 months) pregnant Jaffarabadi buffaloes of $2^{\text {nd }}$ to $4^{\text {th }}$ parity and of nearly identical body size were selected from the herd. They were randomly divided into two equal groups, viz., control and treatment (supplement) groups, each of 20 animals.

The animals of control group were maintained on standard routine farm feeding schedule (20 $\mathrm{kg}$ seasonal green + ad lib dry fodder + concentrate $+50 \mathrm{~g}$ of mineral mixture to meet the DCP \& TDN requirements) during last two months of pregnancy. After calving, the level of compounded concentrate fed was @ 50 per cent of milk produced. The buffaloes under treatment group received additional nutritional supplements orally daily with $50 \mathrm{~g}$ of chelated multi-minerals (AAU, Anand) and $150 \mathrm{~g}$ of bypass fat (Sunegry, Polchem, Malaysia) with concentrates for 6 weeks prepartum and 2 weeks postpartum. Then the bypass fat was increased as per the milk production@15 g/litre of milk produced maximum up to $200 \mathrm{~g} / \mathrm{head} /$ day till 60 days postpartum. 
Animals of both control and treatment groups were subjected to per rectal palpation on day $7,15,30,45$ and 60 postpartum to assess uterine involution by using hand calibration technique of Scully et al., (2013). Uterine position was scored on a $0-3$ scale $[0=$ uterus and uterine horn returned to the previously non-gravid state (within the pelvic canal) and $1-3=$ uterine body and horns falling further over the pelvic brim i.e., between the pelvic brim and abdominal cavity]. Similarly the size of uterine horns (comparative size; > cervix 1; $=$ cervix $2 ;<$ cervix 3 ), and tone and consistency of uterine horns (low tonicity 1; moderate tonicity 2; good tonicity 3) were graded.

The transrectal ultrasonography was performed using a real-time B-mode ultrasound scanner (DB355M, IMAGOS, ECM, France) equipped with a 5.0-7.5 MHz linear array transducer. The transducer was positioned dorsally and parallel above the cervix and relevant measurements of cervical diameter and thickness were recorded. Approximately $10 \mathrm{~cm}$ ahead from the gross bifurcation, the uterine horn diameter and wall thickness were measured as per the guidelines of Melendez et al., (2004) for both the involuting gravid and non-gravid horns on each day of rectal palpation. The caruncles located approximately at the same position of scanning for uterus were measured for its length and width on day 7 and 15 postpartum. During the scanning, the relevant images were frozen on the screen and the measurements were taken using an inbuilt calliper system. The data generated were analysed statistically.

\section{Results and Discussion}

\section{Findings on Trans-Rectal Palpation}

On per rectal palpation by day 7 postpartum, gravid and non-gravid uterine horns were lying cranial and ventral to pelvic brim in abdominal cavity as large, soft, flabby water bag like without any tonicity and elasticity in all the animals, irrespective of groups studied. The gravid uterine horn was not palpable up to its full length but the non-gravid horn could be palpated to its full length with little difficulties, in both the groups of animals. By day 15 , in comparison to the location of gravid horn, the non-gravid horn and the cervix were found to be nearer to the pelvic brim in buffaloes in both the groups. The horns appeared to resemble a water-hose having soft consistency with a mild increase in tone and elasticity. In all the animals, the cervix and the non-gravid horns were found to be on the pelvic brim.

The gravid horn, however, was either touching the pelvic brim or suspended in the abdominal cavity. These findings were in agreement with the observations of Butchaiah et al., (1975) and Nakhashi et al., (2012) in buffaloes wherein the majority of animals had genitalia within the pelvic cavity between days 14 and 18 postpartum. Morrow et al., (1969) also reported that the uterus returned to a definable state of palpation cranial and ventral to the pelvis at 8-10 days postpartum with completed uterine involution in 20 to 25 days in exotic dairy cattle.

By the end of fourth week, the similar trend for position was observed indicative of gravid horn getting involuted later as compared to the non-gravid horn. By day 30, the horns appeared to be symmetrical and located within the pelvic cavity. Practically, by the end of $6^{\text {th }}$ week (42-45 days postpartum), the gravid and non-gravid horns as well as cervix were found to be located in the pelvic cavity and involuted almost to their previous non-gravid state. These observations concurred well with many previous reports on uterine involution in different breeds of buffalo (Butchaiah et al., 1975; Devaraj, 1982; Khatri et al., 2013; Kalasariya et al., 2017). 
The position scores (0-3) of the cervix and gravid and non-gravid uterine horns and their relative size as well as uterine tonicity scores recorded at different days postpartum in Jaffarabadi buffaloes under control and nutrient supplemented (treatment) groups revealed that the position scores were almost same in animals of both the groups at different time intervals and the gross uterine and cervical involution was completed by day 30 with improved uterine tonicity till day 45 postpartum in most of the animals. Similar observations were made by Scully et al., (2013) and Theodore et al., (2016) in cattle.

On day 7 postpartum, the gravid and nongravid uterine horns were found to be larger than the cervix in both the groups. By day 15 , in control group, $18(90.00 \%)$ animals had the past gravid horns larger than the cervix and three animals had the uterine horn similar to the cervix. In treatment group, $17(85.00 \%)$ animals had the gravid uterine size apparently larger as compared to the cervix, while the 5560 per cent of non-gravid uterine horns had the size comparable to the cervix by day 15 postpartum. By day 30 postpartum onwards, both the gravid as well as non-gravid horns had their size comparatively smaller than the cervix in animals of both the groups, with 2 and 1 animal of control and supplement groups having past gravid horn size equal to cervix at day 30 postpartum.

The decrease in size of uterine horns was observed to be faster up to day 15 to 30 postpartum and thereafter it decreased very marginally. The gross involution of the genitalia was observed to be completed by day $37.00 \pm 0.56$ and $32.75 \pm 0.57 \quad(p<0.05)$ in buffaloes under control and treatment groups with significant effect of nutrients supplemented. The increasing trend in the tonicity, elasticity and curling of horns was observed from day 15 postpartum with firm consistency on day 30 postpartum for all the animals under both the groups, being more pronounced in treatment group. On day 30 postpartum, the horns evinced decreased tonicity and elasticity (slight doughy consistency), with lesser curling of horns. On day 45 postpartum, the tonicity, elasticity and curling of the uterine horns were observed to be increased again. These findings were in accordance with the reports of Sutaria et al., (2014) and Theodore et al., (2016) in bovines.

The present findings of gross uterine involution (32.75 to 37.00 days) observed in Jaffarabadi buffaloes are in close agreement with the earlier results of several researchers (Devraj, 1982; Usmani et al., 2001; Presicce et al., 2005; Khatri et al., 2013; Kalasariya et al., 2017). The mean time recorded for uterine involution in the present study was, however, found to be comparatively higher than the values reported by Suthar et al., (2004) and Nakhashi et al., (2012).

\section{Trans-Rectal Ultrasonographic Evaluation}

\section{Echogenicity of reproductive tract}

Upon USG scanning on day 7, the wall of the cervix appeared as bright hyperechoic structure, while its lumen was found to be hypoechoic with bright hyperechoic spots. The bright hyperechoic spots present in the lumen of the cervix represented the cervical folds.

The present findings are fully substantiated by the observations of Sutaria et al., (2014) in Kankrej cattle and Parikh et al., (2017) in Mehsana buffaloes. The hyperechogenicity of the cervix observed in the study seemed to be due to firm and solid structures of the cervix yielding good echogenicity. The lumen of the cervix was depicted as hypoechogenic area. The cervix was found to be reduced in diameter considerably by day 7 with constant reformation of the cervical folds evinced through echogenecity. 
Plate.1 Sonograms of cervix, past gravid and non-gravid uterine horns and caruncles on day 7 and 15 postpartum in Jaffarabadi buffaloes

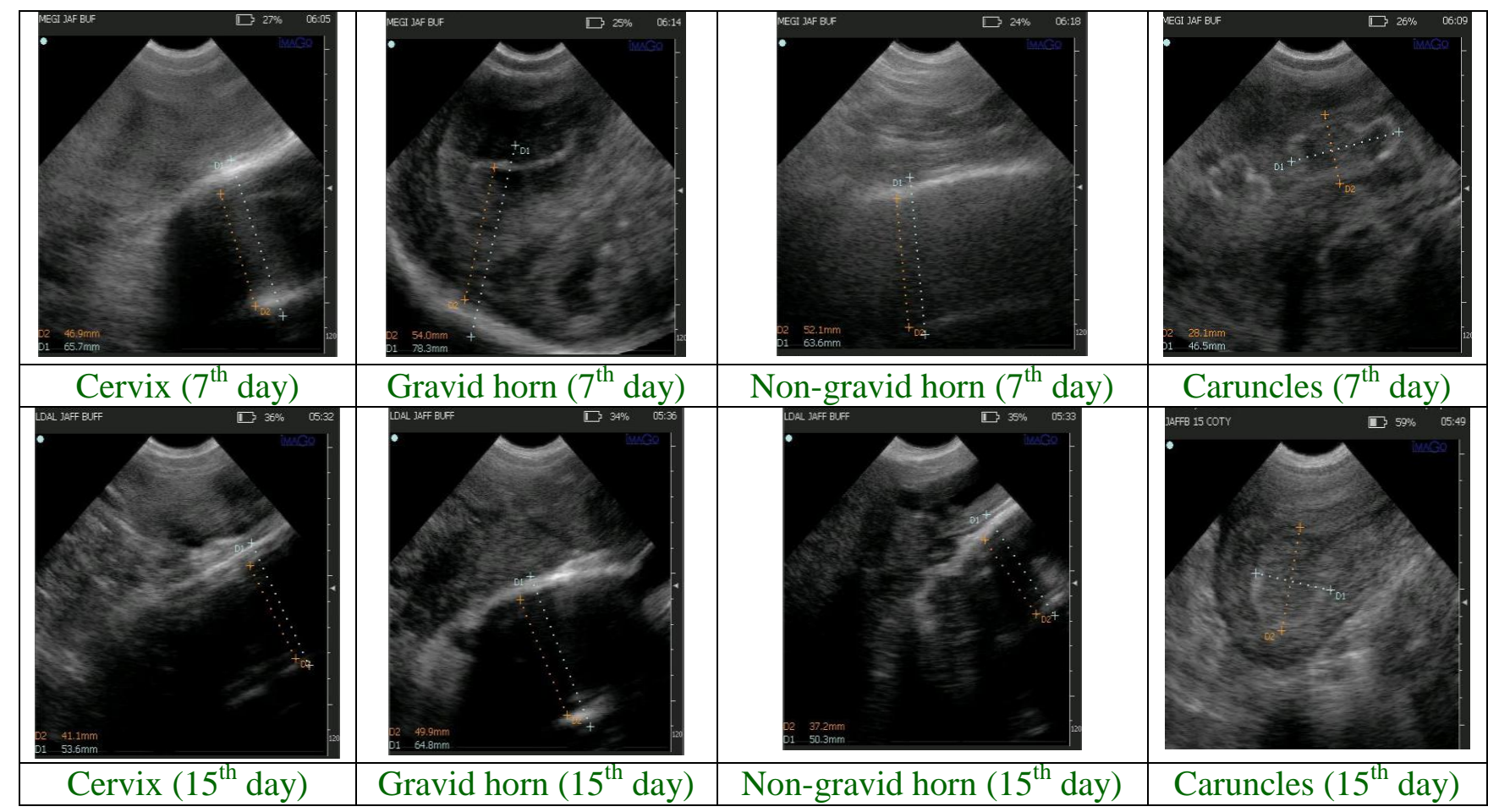

Plate.2 Sonograms of cervix, past gravid and non-gravid uterine horns and caruncles on day 30 and 45 postpartum in Jaffarabadi buffaloes

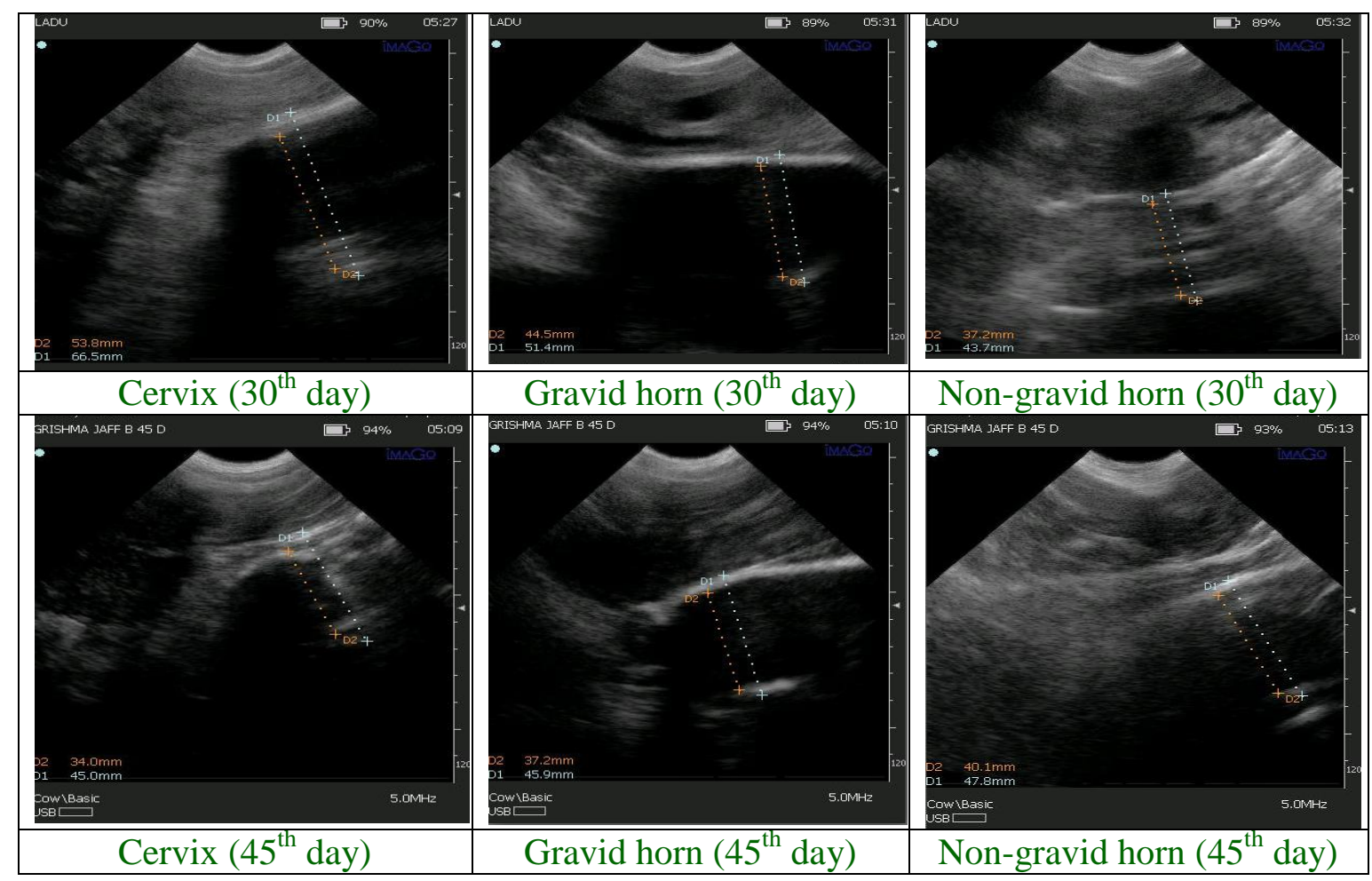


Table.1 Position (scores 0-3) of the cervix and gravid and non-gravid uterine horns in postpartum Jaffarabadi buffaloes under control and nutrient supplemented (treatment) groups

\begin{tabular}{|c|c|c|c|c|c|c|}
\hline \multirow{2}{*}{$\begin{array}{l}\text { Days } \\
\text { Postpartum }\end{array}$} & \multicolumn{2}{|l|}{ Cervix } & \multicolumn{2}{|c|}{ Gravid horn } & \multicolumn{2}{|c|}{ Non-gravid horn } \\
\hline & $\begin{array}{l}\text { Control } \\
(\mathrm{n}=20)\end{array}$ & $\begin{array}{l}\text { Treatment } \\
(\mathrm{n}=20)\end{array}$ & $\begin{array}{l}\text { Control } \\
(\mathrm{n}=20)\end{array}$ & $\begin{array}{l}\text { Treatment } \\
(\mathrm{n}=20)\end{array}$ & $\begin{array}{l}\text { Control } \\
(\mathrm{n}=20)\end{array}$ & $\begin{array}{l}\text { Treatment } \\
(\mathrm{n}=20)\end{array}$ \\
\hline 7 & $3.0 \pm 0.0$ & $3.0 \pm 0.0$ & $3.0 \pm 0.0$ & $3.0 \pm 0.0$ & $3.0 \pm 0.0$ & $3.0 \pm 0.0$ \\
\hline 15 & $2.0 \pm 0.0$ & $2.0 \pm 0.0$ & $2.5 \pm 0.0$ & $2.5 \pm 0.0$ & $2.0 \pm 0.0$ & $2.0 \pm 0.0$ \\
\hline 30 & $0.5 \pm 0.0$ & $0.5 \pm 0.0$ & $1.0 \pm 0.0$ & $1.0 \pm 0.0$ & $0.5 \pm 0.0$ & $0.5 \pm 0.0$ \\
\hline 45 & $0.0 \pm 0.0$ & $0.0 \pm 0.0$ & $0.0 \pm 0.0$ & $0.0 \pm 0.0$ & $0.0 \pm 0.0$ & $0.0 \pm 0.0$ \\
\hline
\end{tabular}

Table.2 Mean $( \pm \mathrm{SE})$ diameter and thickness of cervix, gravid and non-gravid horns measured by USG from day 7 to day 60 postpartum in Jaffarabadi buffaloes

\begin{tabular}{|l|l|l|l|l|l|l|}
\hline $\begin{array}{l}\text { Days } \\
\text { post- } \\
\text { partum }\end{array}$ & $\begin{array}{l}\text { Cervix } \\
\begin{array}{l}\text { Diameter } \\
(\mathrm{cm})\end{array}\end{array}$ & $\begin{array}{l}\text { Wall } \\
\text { thickness } \\
(\mathrm{cm})\end{array}$ & $\begin{array}{l}\text { Diameter } \\
(\mathrm{cm})\end{array}$ & $\begin{array}{l}\text { Wall } \\
\text { thickness } \\
(\mathrm{cm})\end{array}$ & $\begin{array}{l}\text { Diameter } \\
(\mathrm{cm})\end{array}$ & $\begin{array}{l}\text { Wall } \\
\text { thickness } \\
(\mathrm{cm})\end{array}$ \\
\hline $\mathbf{7}$ & $6.51 \pm 0.02^{\mathrm{a}}$ & $1.86 \pm 0.02^{\mathrm{a}}$ & $7.78 \pm 0.03^{\mathrm{a}}$ & $2.48 \pm 0.02^{\mathrm{a}}$ & $6.31 \pm 0.02^{\mathrm{a}}$ & $1.34 \pm 0.02^{\mathrm{a}}$ \\
\hline $\mathbf{1 5}$ & $5.25 \pm 0.03^{\mathrm{ab}}$ & $1.26 \pm 0.01^{\mathrm{b}}$ & $5.18 \pm 0.02^{\mathrm{b}}$ & $1.32 \pm 0.02^{\mathrm{b}}$ & $5.02 \pm 0.01^{\mathrm{b}}$ & $1.20 \pm 0.03^{\mathrm{ab}}$ \\
\hline $\mathbf{3 0}$ & $3.80 \pm 0.02^{\mathrm{bc}}$ & $1.18 \pm 0.01^{\mathrm{b}}$ & $4.85 \pm 0.03^{\mathrm{c}}$ & $0.70 \pm 0.02^{\mathrm{c}}$ & $4.37 \pm 0.03^{\mathrm{c}}$ & $0.89 \pm 0.01^{\mathrm{bc}}$ \\
\hline $\mathbf{4 5}$ & $3.32 \pm 0.03^{\mathrm{c}}$ & $1.13 \pm 0.01^{\mathrm{b}}$ & $4.48 \pm 0.03^{\mathrm{c}}$ & $0.67 \pm 0.01^{\mathrm{c}}$ & $4.33 \pm 0.03^{\mathrm{c}}$ & $0.67 \pm 0.01^{\mathrm{c}}$ \\
\hline $\mathbf{6 0}$ & $3.30 \pm 0.03^{\mathrm{c}}$ & $1.11 \pm 0.01^{\mathrm{b}}$ & $4.43 \pm 0.03^{\mathrm{c}}$ & $0.66 \pm 0.01^{\mathrm{c}}$ & $4.32 \pm 0.04^{\mathrm{c}}$ & $0.66 \pm 0.01^{\mathrm{c}}$ \\
\hline
\end{tabular}

Means bearing uncommon superscripts within the column differ significantly $(\mathrm{p}<0.05)$.

The echogenicity of the cervix became even more pronounced with the hyperechoic cervical wall and the cervical folds being maintained in subsequent days postpartum (Plate 1 \& 2). These findings were in accordance with the observations of Wehrend et al., (2003) and Theodore et al., (2016).

Sonography of the gravid uterine horns on $7^{\text {th }}$ day postpartum revealed hyperechoic wall and the lumen was anechoic with some hyperechoic spots. On the later stages, the gravid uterine horns were seen as hyerechoic wall and hypoechoic lumen. Similar findings were also observed for non-gravid uterine horns. By day 45 postpartum, the echogenicity of the uterine horns was much pronounced revealing the wall to be hyperechoic, whereas the lumen was hypoechoic (Plate 1 \& 2). Lamb (2003) opined that uterine tissue of the non-pregnant cycling cows appears as an echogenic structure. Gulvane (2005) and Theodore et al., (2016) reported that during $2^{\text {nd }}$ week postpartum, uterus was filled with lochia which gave hyperechoic and hypoechoic pattern on the screen, which substantiated the present findings.

The snowy appearance of the uterine lumen filled with lochia mixed with necrotic tissue debris was because of the differences in their echogenicity. The present findings were in agreement with the observations made by Kamimura et al., (1993) and Theodore et al., (2016), who visualized the snowy appearance of lochia until day 14-18 postpartum on ultrasonic scanning of the Holstein and crossbred cows, respectively, with initially less echogenic uterine horn becoming more 
echogenic with the progress in uterine involution.

The scanned uterine caruncles on day 7 postpartum were represented as a bright hyperechoic structures resembling mushroom, protruding in the anechoic uterine lumen, encircled with bright visible hyperechoic line. The texture of the caruncles was similar afterwards, but highly reduced in dimensions, i.e., in length and width (Plate 1). These findings corroborated with the reports of Gulvane (2005) and Jadhav (2005). However, Sutaria et al., (2014), Theodore et al., (2016) and Parikh et al., (2017) observed the caruncles as bright hyperechoic structures having hypoechoic spots in bovine.

Diameter and thickness of cervix, and gravid \& non-gravid uterine horns

There were no significant differences between control and treatment groups at any of the intervals postpartum for diameters and wall thickness of cervix or past gravid and nongravid uterine horns. Hence the overall pooled mean values of cervix and gravid as well as non-gravid horns' diameters and wall thickness observed during different periods postpartum are presented, irrespective of groups, in Table 2.

The mean diameter of the cervix recorded in animals on day 7 postpartum decreased significantly $(\mathrm{p}<0.05)$ on days 15 and 30 postpartum, and thereafter the reduction was non-significant. The mean thickness of the cervical wall recorded on days $7,15,30,45$ and 60 postpartum showed a progressive and significant reduction $(\mathrm{p}<0.05)$ with advancing postpartum period till day 15 , and thereafter no further reduction was noted between day 30 and 60 postpartum (Table 2). This trend in reduction in the day-wise mean cervical diameters and thickness was in accordance with the observations reported by Sinha et al.,
(2002), Sutaria et al., (2014) and Theodore et al., (2016) in cows; and Kranthi (2016) and Parikh et al., (2017) in buffaloes. This trend in reduction in cervical diameter throughout postpartum period is physiologically normal and similar, irrespective of breed and size. These observations on cervical wall thickness indicated that, as the changes in cervical diameter did not vary significantly after day 30 postpartum, the cervical involution was completed by day 30 postpartum. Yet the fact is that the involution process was still proceeding as the wall thickness of the cervix continued to reduce nominally till 45 days postpartum.

The mean diameters of gravid and non-gravid uterine horns also reduced significantly $(\mathrm{p}<0.05)$ and progressively from day 7 to day 15 and 30 postpartum, and thereafter the decline was non-significant. The mean thickness $(\mathrm{cm})$ of wall of the gravid and nongravid uterine horns also showed statistically significant $(\mathrm{p}<0.05)$ reduction from day 7 to day 30 postpartum (Table 2). The diameters of the completely involuted gravid and nongravid uterine horns in the present study corroborated with the observations of Sinha et al., (2002). However, the present observations were comparatively higher than the findings of Jadav (2005), Sutaria et al., (2014) and Parikh et al., (2017). The observed difference could be due to the breed and observer's variation.

\section{Length and width of caruncles}

The mean caruncular lengths $(\mathrm{cm})$ in Jaffarabadi buffaloes on day 7 and 15 postpartum were found to be $4.59 \pm 0.04$ and $2.37 \pm 0.03 \mathrm{~cm}$, respectively, the difference being significant $(p<0.05)$. The mean caruncular widths $(\mathrm{cm})$ in animals on day 7 and 15 postpartum were $2.72 \pm 0.06$ and $1.42 \pm 0.02 \mathrm{~cm}$, respectively, which also differed significantly $(\mathrm{p}<0.05)$. These findings 
for reduction in length and width of caruncles from day 7 to 15 postpartum were in agreement with Gulvane (2005), Sutaria et al., (2014) and Parikh et al., (2017). They all reported that the dissolution and sloughing of the caruncles was generally completed by 12 days postpartum and they returned to nearly normal original size by $2^{\text {nd }}$ to $3^{\text {rd }}$ week postpartum in bovines.

Overall, the mean uterine involution time recorded in the present study is in agreement with the findings (28-40 days) of Usmani et al., 2001; Presicce et al., 2005; Khatri et al., 2013; Kranthi (2016). However, it was found to be slightly lower as compared to the values (40-45 days) reported by Heppelmann et al., (2013) and Scully et al., (2013). The faster involution of uterus was positively correlated with early onset of postpartum estrus and conception rate in animals under study, since by 120 days postpartum, 50 and $85 \%$ animals in control and treatment group had conceived.

\section{Acknowledgement}

We thank the Officer in Charge of CBF, JAU, Junagadh and their staff for permitting to use their animals and kind cooperation as well as PI, Dr. A.J. Dhami of "AICRP on nutritional \& physiological interventions for enhancing reproductive performance in animals" of AAU, Anand for financial support during this study.

\section{References}

Bacjsy, A.C., Szenci, O. Doornebal, A., Weijden, G., Csorba, C., Kocsis, L., Szucs, I. Ostgard, S. and Taverne, M.A.M. 2005. Characteristics of bovine early puerperal uterine contractibility recorded under farm conditions. Theoriogenology, 64, 99-111.

Butchaiah, V., Tomar, N.S. and Singh, B.P. 1975. The behaviour of estrous cycle in buffaloes. Indian. Vet J., 52, 97-102.
Devraj, M. 1982. Blood serum profile in calves and postpartum buffaloes (Surti breed) with associated peridata to reproductive efficiency. Ph.D Thesis, Gujarat Agricultural University, Anand, India.

Gulvane, S.U. 2005. Use of Ultrasonography in Animal Reproduction. Training Manual. Dept. of Gynaecology, Bombay Veterinary College, Parel, Mumbai. Pp. 5-11.

Heppelmann, M., Weinert, M., Brommling, A., Piechotta, M., Hoedemaker, M. and Bollwein, H. 2013. The effect of puerperal uterine disease on uterine involution in cows assessed by doppler sonography of the uterine arteries. Anim. Reprod. Sci., 143, 1-7.

Jadhav, P.D. 2005. Study of postpartum resumption of ovarian activity and uterine involution, monitored by ultrasonography and hormonal assays in Gir and crossbred cows. Ph.D. Thesis, MAFSU, Nagpur, India.

Kalasariya, R.M., Dhami, A.J., Hadiya, K.K., Borkhatariya, D.N. and Patel, J.A. 2017. Effect of peripartum nutritional management on plasma profile of steroid hormones, metabolites and postpartum fertility in buffaloes, Veterinary World, 10(3), 302-310.

Kamimura, S., Ohgi, T., Takahashi, M. and Tsukamoto, T. 1993. Postpartum resumption of ovarian activity and uterine involution monitored by ultrasonography in Holstein cows. J. Vet. Med. Sci., 55, 643-647.

Khatri, P., Tunio, S.A., Kaka, I., Samo, M.U., Bhutto, B. and Memon, M.R. 2013. Effect of exogenous $\mathrm{PGF}_{2} \alpha$ and oxytocin on postpartum anestrus and involution in Kundhi buffaloes. J. Anim. Prod. Adv., 3, 158-163.

Kranthi, K.Y. 2016. Ultrasonographic evaluation of uterine involution and postpartum cyclicity in graded Murrah buffaloes (bubalus bubalis). M.V.Sc. Thesis, Sri Venkateswara Veterinary University, Tirupati, AP, India.

Lamb, G.C. 2003. Reproductive ultrasound for management of beef cattle. In: Proc. VII Conference Focusing on Production and Reproduction of Cattle. Uberlandia, Brazil. pp.183-193.

Melendez, P., McHale, J., Bartolome, J., Archbald, L.F. and Donovan, G.A. 2004. Uterine involution and fertility of Holstein 
cows subsequent to early postpartum $\mathrm{PGF}_{2} \alpha$ treatment for acute puerperal metritis. $J$. Dairy Sci., 87, 3238-3246.

Morrow, D.A., Roberts, S.J. and McEntee, K. 1969. Postpartum ovarian activity and involution of uterus and cervix in dairy cattle. II: Involution of uterus and cervix. Cornell Vet., 59: 190-198.

Nakhashi, H.C., Suthar, B.N., Panchasara, H.H. and Kavani, F.S. 2012. Fertility response in relation to gross uterine involution and $\mathrm{GnRH}$ supplementation in Mehsani buffaloes. GAU Res. J., 37(1), 65-69.

Noakes, D.E. 2001. Endogenous and exogenous control of ovarian cyclicity. In: Arthur's Veterinary Reproduction and Obstetrics. D.E. Noakes, T.J., Parkinson and C.W. Gary (eds), W.B. Saunders Company Ltd., England, pp. 3-53.

Parikh, S.S., Suthar, B.N., Sutaria, T.V., Savaliya, B.D. and Makwana, R.B. 2017. Ultrasonographic evaluation of uterine involution in postpartum Mehsana buffaloes. Bull. Environ. Pharm. Life Sci., 6(1), 38-45.

Presicce, G.A., Bella, A., Terzano, G.M., Santis, G.D. and Senatore, E.M. 2005. Postpartum ovarian follicular dynamics in primiparous and pluriparous Mediterranean Italian buffaloes (Bubalus bubalis). Theriogenology, 63, 1430-1439.

Salma, H., Tainturier, D., Chemli, J., Zaiem, I. and Bencharif, J. 1999. Uterine involution in domestic females: A comparative study. Revue-de-medecine-Veterinaire, $\quad$ 150(10), 779-790.

Scully, S., Maillo, V., Duffy, P., Kelly, A.K., Crowe, M.A., Rizos, D. and Lonergan, P. 2013. The effect of lactation on postpartum uterine involution in Holstein dairy cows. Reprod. Dom. Anim., 48, 888-892.
Setia, M.S., Duggal, R.S. and Singh, R. 1992. Biochemical constituents of blood in buffaloes and cows during late pregnancy and different stages of lactation - A longitudinal study. Buffalo J., 8(2), 123-129.

Sinha, V.K., Singh, B. and Sinha, A.K. 2002. Management of postpartum reproduction in crossbred cows with Dinoprost. The Indian Journal of Animal Reproduction, 23(1), 2124.

Sutaria, T.V., Suthar, B.N., Nakhashi, H.C., Panchasara, H.H., Chauhan, P.M. 2014. Ultrasonographic evaluation of involuting reproductive tract in postpartum Kankrej cows. Intas Polivet, 15(2), 393-395.

Suthar, B.N., Suresh Kumar and Kavani, F.S. 2004. Time dynamics of uterine involution in Mehsani buffaloes: A clinical study. Intas Polivet, 5(2), 166-168.

Theodore, V.K., Panchal, M.T., Dhami, A.J., Hadiya, K.K., Shah, S.V. and Buhecha, K.V. 2016. Whether peripartum nutritional supplementation influence the uterine involution and postpartum fertility in crossbred cows. Int. J. Adva. Vet. Sci. \& Technol., 5(2), 275-284.

Usmani, R.H., Ahmed, N., Shafiq, P. and Mirza, M.A. 2001. Effect of sub-clinical uterine infection on cervical and uterine involution, estrous activity and fertility in postpartum buffaloes. Theriogenology, 55, 563-571.

Wehrend, A., Failing, K. and Bostedt, H. 2003. Cervimetry and ultrasonographic observations of the cervix regression in dairy cows during the first 10 days postpartum. $J$. Vet. Med. A. Physiol. Pathol. Clin. Med. 50(9), 470-473.

\section{How to cite this article:}

Vala K. B., F. S. Kavani, R. J. Raval and Tank P. H. 2018. Evaluation of Uterine Involution by Rectal Palpation and Ultrasonography in Peripartum Nutritional Supplemented Jaffarabadi Buffaloes. Int.J.Curr.Microbiol.App.Sci. 7(06): 1955-1963. doi: https://doi.org/10.20546/ijcmas.2018.706.232 